\title{
Characterization of Bauhinia monandra Seed and Pod for Bioenergy Potential
}

\author{
Oluwasina $0 . \mathrm{O}^{1 *}$, Bello L. $\mathrm{A}^{1}$, Ayodele $\mathrm{O}^{2}$ and Ojo $0 . \mathrm{O}^{3}$
}

\begin{abstract}
In this research, Bauhinia monandra seed and pod were investigated for the first time as a source for bioenergy production. Proximate analysis revealed that the biomass seed contains high volatile matter of $88.96 \%$ and pod $92.64 \%$, the low ash content of $3.16 \%$ for the seed and $0.89 \%$ for the pod, with fixed carbon of $1.87 \%$ for seed and $0.71 \%$ for the pod. The ultimate analysis showed carbon, sulfur, and hydrogen are $41.45 \%, 1.79 \%$ and $6.28 \%$ for the seed, while the pod had $42.25 \%, 1.77 \%$, and $6.21 \%$ respectively. Higher Heating Value ranges from 14.26 - $14.69 \mathrm{MJ} / \mathrm{kg}$ were obtained for the biomass using three mathematical formulas. The Pyrolysis behavior of the biomass revealed four degradation peaks attributed to the removal of water molecules and the degradation of hemicellulose, cellulose, and lignin respectively. The kinetic parameters (activation energy (Ea) and frequency factor (A) determined from TG/DTG data revealed a relatively high Ea (35.5 $-41.56 \mathrm{KJ} / \mathrm{mol}$ ). The structural composition of the seed indicated $43.50 \%$, cellulose, $20.00 \%$ hemicellulose, $19.50 \%$ lignin, and $16.00 \%$ extractive material, and pod had $37.50 \%$ cellulose, $33.50 \%$
\end{abstract}

${ }^{1}$ Department of Chemistry, Federal University of Technology, Akure, Ondo State, Nigeria

${ }^{2}$ Department of Chemistry, Ekiti State University, Ado-Ekiti, Ekiti State, Nigeria

${ }^{3}$ School of Chemistry and Physics, University of KwaZulu-Natal, Westville Campus, South Africa

*Corresponding author; email: oooluwasina@futa.edu.ng hemicellulose, 17. $50 \%$ lignin and $10.23 \%$ extractive material. The elemental composition of revealed that the seed contained $\mathrm{O}, \mathrm{F}, \mathrm{Si}, \mathrm{Cl}, \mathrm{P}$, $\mathrm{Mg}, \mathrm{K}, \mathrm{Ca}$ while pod also contained all with exception of $\mathrm{Cl}$ and $\mathrm{P}$. The SEM revealed that the pod is straight fiberlike material while the seed was a roundish ball like material. From the $\mathrm{HHV}$ and the Ea, with other analysis done Bauhinia monandra seed and pod could be good potential for biofuel production.

\section{KEYWORDS}

Bauhinia monandra, Ultimate-analysis, Chemical composition, Thermogravimetry, Morphological, proximate

\section{INTRODUCTION}

The environmental degradation and socioeconomic setbacks associated with the exploration and exploitation of fossil fuel has led to the search and development of sustainable energy systems that are eco-friendly and economically viable. Also, the energy insecurity due to the increasing depletion of crude oil necessitated a search for alternatives because of the indispensable role of energy supply in a nation's development (Mohammed et al., 2015).

In a bid to salvage this ongoing and looming damage on the environment and humanity, many developing countries have delved into the application of biomass for energy production. The structural composition, even distribution and low amount of sulfur, nitrogen, and ash in lignocellulosic biomass have made them a good source of energy with economic viability and environmental sustainability (Sarfraz et al., 2009). 
Biomass can be classified into four groups and they are (1) wood and woody biomass e.g. silvicultural crops. (2) herbaceous and agricultural biomass e.g. grasses, straws and other residues (3) aquatic and marine biomass e.g. algae, water hyacinth, aquatic weeds, etc. and (4) Wastes e.g. municipal solid waste, animal waste and industrial waste (Vassilev et al., 2010). Biomass has gained a wide application in the production of energy due to its renewable nature and much availability. They are used for heating (e.g. process heat in bioprocess industries), cooking, transportation (e.g. ethanol fuel) and for electric power generation (Baskar et al., 2012). The biomass (Bauhinia monandra seed and pod) under investigation can be classified under herbaceous biomass.

The genus Bauhinia monandra consists of about 300 species, belonging to the family of Leguminosae (Caesalpinioideae) are cultivated in the tropical regions of the world. Bauhinia monandra (Kurz) is an ornamental tree commonly found in West Africa and India (Agbede, 2006). It is a ubiquitous tree characterized by large leaves, pink and white flowers with one large anther and very persistent pods (Bizzo et al., 2014). The nonedibility of this plant justifies its usage for bioenergy production since it poses no threat to food security. Hence, its utilization will boost the economy of the energy sector without interfering with the availability of food products. Also, the ubiquity nature of the plant makes it a good potential source for energy production.

At present, biomass usage is estimated at about $14 \%$ of global energy being is the fourth largest energy resource after coal, oil and natural gas (Parikh et al., 2005). In the US, about 10,000 MW were produced from the processing of biomasses such as forest-product industry, agricultural residue, and municipal solid waste. Herbaceous biomass has a comparable calorific value with wood biomass but with a much lower moisture content (Peter, 2001).

Different experimental and instrumental methods such as TGA/DTG, proximate and ultimate analysis, as well as mathematical models such as Higher Heating Values, activation energy, are used to determine the inherent energy of biomass. Higher heating value is a measure of the energy content of biomass (Parikh et al., 2005). Investigation of the thermal decomposition kinetics of the various components in the biomass is necessary for designing gasifiers and pyrolysis reactors (Yang and $\mathrm{Wu}, 2009$ ).

Our interest in Bauhinia monandra plant is due to the lack of comprehensive researches regarding the physicochemical and thermal properties of $B$. monandra seeds and pods have limited their use as sources of biofuel and bioenergy. To the best of our knowledge, this would be the first research work in the energy field done on this plant's seed and pod. Hence, a new prospect of their seed and pod are to be investigated for bioenergy potential. The aim of this study was to investigate the structural and thermochemical properties of Bauhinia monandra seed and pod as a potential source for sustainable biofuel production.

\section{RESULT AND DISCUSSION}

\section{Proximate Analysis and Higher Heating Values}

The proximate analysis and the heating values of Bauhinia monandra seeds and pods resulted are presented in Table 1. The moisture content of Bauhinia monandra seed (6.01\%) was higher than the pod which is $5.77 \%$. The relatively high moisture content in seed compared to pod may be attributed to the nature of the pod since it will contain more fiber content which makes it lose water easily. The moisture content for the seed and pod is comparable with some reported herbaceous biomass such as Moringa pergrina seed husk (4.48 \%), pea pod $(7.00 \%)$ and tea waste (6.50 \%) (Stella-Mary et al., 2016; Salaheldeen et al., 2014). The moisture content of the seed and pod below the recommended value for biomass of less than $12.00 \%$ (Kurchania et al., 2010). The low moisture content of the seed and pod recorded 


\begin{tabular}{|c|c|c|}
\hline Parameters & Seed & Pod \\
\hline $\begin{array}{l}\text { Moisture } \\
\text { content (\%) }\end{array}$ & $6.01 \pm 0.11$ & $5.77 \pm 0.05$ \\
\hline $\begin{array}{l}\text { Volatile matter } \\
\text { (\%) }\end{array}$ & $\begin{array}{l}88.96 \\
1.24\end{array}$ & $92.64 \pm 0.20$ \\
\hline Ash content (\%) & $3.16 \pm 0.34$ & $0.89 \pm 0.18$ \\
\hline Fixed carbon (\%) & $1.87 \pm 1.01$ & $0.71 \pm 0.03$ \\
\hline $\mathrm{HHV}(\mathrm{MJ} / \mathrm{kg})$ & $14.49 \pm$ & $14.26 \pm 0.01$ \\
\hline (I) & 0.20 & \\
\hline $\mathrm{HHV}(\mathrm{MJ} / \mathrm{kg})$ & 14.26 & $14.42 \pm 0.06$ \\
\hline$(2)$ & 0.10 & \\
\hline $\mathrm{HHV}(\mathrm{MJ} / \mathrm{kg})$ & 14.36 & $14.69 \pm 0.04$ \\
\hline (3) & 0.38 & \\
\hline
\end{tabular}

Values are means of three replicate \pm standard deviation

Table 1: Proximate analysis and heating values of Bauhinia monandra seed and pod

in this experiment could be an indication of their suitability as a good source of biomass for combustion or energy since high moisture percentage reduces combustion temperature and facilitate microbial degradation and in so doing reduces the energy content of the biomass sample (Argolo et al., 2004). It also implies that these materials would withstand long storage with less or no microbial degradation.

The result revealed that both the seed and pod have high volatile matter but that of the pod $(92.64 \%)$ is relatively higher compared to the seed $(88.96 \%)$. The high volatile content of the pod could be attributed to its aroma nature, which could be given off easily when under thermal treatment, as compared with the seed without any aroma smell. The value of volatile matter recorded for both seed and pod are higher than those recorded for some popular herbaceous biomass such as Wheat straw $(59.00$ $\%)$, Barley straw (46.00\%), Mischantus gigantus (66.80\%) and Rice straw (79.00\%) (Mckendry, 2002). The difference may be attributable to the variation in the composition of a volatilized organic component in the various biomasses. The high volatile matter could be of advantage during the thermochemical conversion process because the high yield of bio-oil and synthetic gas could be produced.

The ash content of the seed $(3.16 \%)$ is relatively higher than that of the pod $(0.98 \%)$. The higher ash content of the seed could be because it contained more mineral as revealed by the EDX elemental analysis. The seed had eight elements while the pod has six elements as described by EDX analysis. Most of these elements could be converted to inorganic derivatives, thus differences in the ash content. The ash content of the seed compared favorably with that of Loblolly pine $(0.40 \%)$, while that of the pod compared with those of sugarcane bagasse (2.70 $\%)$, corn stover (3.70\%), olive husk (4.00\%) and corn cob (1.00 \%) (Risser, 1981; Dermibas, 1996) The ash content of a biomass is classified as low $(<5.00 \%)$, medium (5.00 $-10.00 \%)$ and high (>10.00\%) (lyer et al., 2002). The ash content of the pod and seed in this research can be classified as low. The low ash content of the seed and pod could mean that when such as plant is used during thermal conversion there may be no problem of slag formation at the bottom of the furnace provided that $\mathrm{Ca}$ and $\mathrm{K}$ content is little or absent.

The fixed carbon for seed $(1.87 \%)$ is higher than that of the pod $(0.71 \%)$. The disparity between fixed carbon content of the seed and pod may be as a result of differences in their morphology and chemical compositions. The low fixed carbon content of the pod may also have contributed to its low ash content since the carbon residue also contributes to the ash content. These values do not fall within the common range of $7 \%$ and 20 $\%$ for common biomasses; hence, they have low fixed carbon content (García et al., 2012). The difference may be attributed to different soil properties, species differentiation, planting technology and climate conditions under which Bauhinia monandra plants grow. Also, the difference may be attributed to the fact that many biomasses have a good system for transporting inorganics but seeds and pods have a poor transport system. 
Higher heating value is an important parameter in evaluating the quality of biomass to be used as a feedstock for bio-energy. The Higher Heating Values (HHV) of the samples was calculated using three different mathematical formulas as stated below:

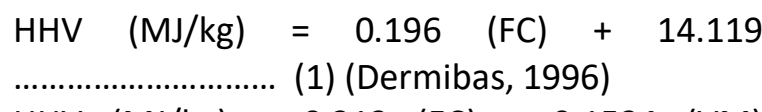

$\mathrm{HHV}(\mathrm{MJ} / \mathrm{kg})=0.312(\mathrm{FC})+0.1534(\mathrm{VM})$ (2) (Parikh et al., 2005)

$\mathrm{HHV}(\mathrm{MJ} / \mathrm{kg})=0.3536(\mathrm{FC})+0.1559(\mathrm{VM})-$ 0.0078 (A) ...... (3) (Parikh et al., 2005)

Where FC is the Fixed Carbon Content; VM is the volatile matter and $\mathrm{A}$ is the ash content. The calculated Higher Heating Value (HHV) varied between (14.26 -14.49 MJ/kg) for the seed and $(14.26$ - $14.69 \mathrm{MJ} / \mathrm{kg})$ for the pod using equations, 1,2 and 3 respectively. There is no much difference in the HHV's for the pod and seed using the three mathematical equations. The HHV result obtained for the seed and pod falls in the range of Higher Heating Values that has been reported by other authors for several herbaceous biomass such as Cocoa Pod Husk (14.25 MJ/kg), Rice Husk (16.47 MJ/kg), Sugar Cane Bagasse (17.32 MJ/kg), Spire mint (14.96 $\mathrm{MJ} / \mathrm{kg})$, Halzelnut shell $(20.21 \mathrm{MJ} / \mathrm{kg}$ ) etc. and the value is always between $14 \mathrm{MJ} / \mathrm{kg}-20 \mathrm{MJ} / \mathrm{kg}$ (Martinez-Angel et al., 2015; Suarez et al., 2000) . The relatively large HHV for the biomass samples may be attributed to their low ash content $(0.89-3.16 \%)$ and high carbon content $(41.45-42.25 \%)$ as revealed by the ultimate analysis (Table 2).

\section{Ultimate analysis}

The ultimate analysis of Bauhinia monandra seed and pod was presented in Table 2 . The ultimate analysis result revealed that both seed and pod have very close values.

\begin{tabular}{lll}
\hline Parameters (\%) & Seed & Pod \\
\hline Carbon (\%) & $41.45 \pm 0.55$ & $42.25 \pm 1.21$ \\
Hydrogen (\%) & $6.28 \pm 0.03$ & $6.21 \pm 0.14$ \\
Sulfur (\%) & $1.79 \pm 0.05$ & $1.77 \pm 0.04$ \\
H/C (atomic & $0.15 \pm 0.00$ & $0.15 \pm 0.00$ \\
ratio) & & \\
\hline
\end{tabular}

Values are means of three replicate \pm standard deviation

\section{Table 2: Ultimate Analysis of Bauhinia monandra seeds and pods}

The carbon content on a dry basis for the seed $(41.45 \%)$ is reasonable compared to that of the pod (42.25\%). The values obtained in this study were close to that reported for fast-growing herbaceous biomasses such as Miscanthus gigantus (46.82\%), Rape straw (46.90\%), Barley straw (46.75\%) and Wheat straw (45.06 \%) (Diaz-Ramirez et al., 2012). The reasonably high $\mathrm{HHV}$ of the seed and pod (14.26 - $14.69 \mathrm{MJ} / \mathrm{kg}$ ) may be attributed to its relatively high carbon content (Agbugui et al., 2010).

The result (Table 2) showed similar hydrogen content for both seed (6.28\%) and pod (6.21\%). The values observed for hydrogen are higher than those reported for Reed (pellets) (5.68 \%), Rape straw (5.88 \%), Mischantus gigantus (5.83 $\%)$ and Barley straw (5.68 \%). The hydrogen content values reported in this study are higher than the expected hydrogen content value of $5.70-6.10 \%$ for Herbaceous Agricultural biomass (Vassilev et al., 2010).

The sulfur content recorded a close value for both seed $(1.77 \%)$ and pod (1.79 \%). These values are higher than the values recorded for well-known energy crops like Miscanthus gigantus $(0.15 \%)$, Switch grass $(0.01 \%$ ) (Vassilev et al.,2010). The difference may be attributed in the differences in the elemental composition of various biomasses. The sulfur content of the seed and pod is below a critical value ( $2 \%)$, hence might have a less environmental impact. High sulfur content in biomass samples affects the operational efficiency of heat exchanger due to depositions of sulfate or ashes which are 
generated by $\mathrm{SO}_{2}$ emissions (Mohammed et al., 2015).

The hydrogen to carbon ratio $(\mathrm{H} / \mathrm{C})$ is a term often used to measure the degree of aromaticity and maturation of the biomass/biochar and this is linked to their long-term stability in the environment (Schmidt and Noack, 2000). The $\mathrm{H} / \mathrm{C}$ ratio of pod and seed gave the same value of 0.15 . This value is similar to that reported for Napier grass stem, leaf /stem, and leaf which is $0.124,0.125$ and 0.131 respectively. The higher the $\mathrm{H} / \mathrm{C}$ contents of biomass, the higher the HHV (Adeyinka, 2012). It is noteworthy to state that $\mathrm{H} / \mathrm{C}$ ratio reduces with increasing pyrolysis temperature and retention time due to the formation of $\mathrm{C}$ complex structures and rapid volatilization of the hydrogen content of the biomass (Mukome et al., 2013).

\section{Structural analysis}

The result presented in Table 3 revealed the structural composition of the pod and the seed. Cellulose, hemicellulose, and lignin are regarded as major components of the biomass with an approximate composition of $40-80 \mathrm{wt} \%$ of cellulose, $15-30 \mathrm{wt} \%$ of hemicelluloses and 1025 wt\% of lignin (Carrier et al., 2011). The result of the structural analysis showed that Bauhinia monandra seed contains 43.5 wt\% cellulose, 20 wt\% hemicellulose, 19.5 wt\% lignin, and 16 wt\% extractives while Bauhinia monandra pod contains $37.5 w t \%$ cellulose, 33.5 wt $\%$ hemicellulose, $17.5 \mathrm{wt} \%$ lignin and $10.23 \mathrm{wt} \%$ extractives. The seed contains a higher amount of cellulose, lignin, and extractives than the pod with the exception of hemicellulose. The difference may be attributed to the differences in the structural composition of both materials. The seed has much weight than the pod that is very light in weight. This structural composition of seed is similar to that obtained by (Mohammed et al., 2015) (38.75\% cellulose, $19.76 \%$ hemicellulose, $26.99 \%$ lignin and 12.07 $\%$ extractives) for Napier Grass Stem. A study carried out by (Stella-Mary et al., 2016) (45\% cellulose, $41 \%$ hemicellulose and $3 \%$ Lignin) on pea pod was not in agreement with Bauhinia monandra pod. The non-agreement may be attributed to the difference in morphological characteristics, climate change, soil properties etc. The structural composition of the seed and pod falls in the range of $25.2-51.2 \%$ cellulose, 19.9 - 39.1\%hemicellulose and $14.40-53.00$ \%lignin for several biomasses with potentials for biofuel production (Dermibas, 1996). The lignin content of biomass is one of the parameters for measuring their energy density (Mendu et al., 2011). Thus, the relatively high density of lignin in B. monandra seed and pod (10.23 - 16 wt\%) makes them a potential source for bioenergy.

\begin{tabular}{lllll}
\hline Parameters (\%) & Seed & & Pod & \\
\hline Cellulose (\%) & 43.50 & \pm & 37.50 & \pm \\
& 0.50 & & 0.50 & \\
Hemicellulose (\%) & 20.00 & \pm & 33.50 & \pm \\
& 1.00 & & 1.50 & \\
Lignin (\%) & 19.50 & \pm & 17.50 & \pm \\
& 1.50 & & 0.50 & \\
Extractives (\%) & 16.00 & \pm & 10.23 & \pm \\
& 1.00 & & 0.25 & \\
\hline
\end{tabular}

Values are means of three replicate \pm standard deviation

Table 3: Structural Analysis of Bauhinia monandra seeds and pods

\section{Inorganic Ash composition}

The EDX analysis presented in Table 4 indicated the inorganic ash composition of Bauhinia monandra seed and pod on a dry basis. Inorganic characterization of biomass is needed because they have a great tendency to cause slagging, fouling in the furnace during thermochemical conversion. The analysis indicated the presence of $\mathrm{O}, \mathrm{K}, \mathrm{Ca}, \mathrm{Mg}, \mathrm{F}, \mathrm{Cl}$, Si in both seed and pod but $\mathrm{P}$ and $\mathrm{Cl}$ are not detectable in the pod. Oxygen is highest in both seed (39.73\%) and pod (43.33 $\%)$; high content of $\mathrm{K}$ in the pod $(42.04 \%)$ compared to the seed $(22.39 \%)$ and $\mathrm{Ca}$ is relatively high in the seed ( $17.35 \%$ ) compared to the pod $(6.61 \%)$. The values recorded for nonmetals in both seed and pod ( $\mathrm{Si}, \mathrm{P}, \mathrm{Cl}$, and $\mathrm{F}$ ) are less than $3.5 \%$ with the exception of $O$ which ranges between $(39.73-43.33 \%)$. The values recorded for the inorganic composition is significantly different from the values reported 
for fast-growing biomasses as presented in Table 4. The difference may be a result of factors such as the ability of plant biomass to uptake minerals in water and soil, the nature of the soil, doses of applied fertilizers and pesticides etc. The reaction of highly concentrated alkali metals in the presence of non-metals such as $\mathrm{Si}$ and $\mathrm{Cl}$ has a great tendency in causing significant fouling and slagging during thermochemical conversion (Diaz-Ramirez et al., 2012). Thus, there is a tendency for the occurrence of fouling and slagging in the thermochemical conversion process of Bauhinia monandra seed due to the high concentration of $\mathrm{K}, \mathrm{Ca}$ and $\mathrm{Mg}$ in the presence of $\mathrm{Si}$ and $\mathrm{Cl}$. However, this tendency can be averted if the temperature of the medium is raised to $800{ }^{\circ} \mathrm{C}$ (Raclavska et al., 2011). There is also a possibility of the alteration of ash melting behavior due to the availability of $\mathrm{P}(1.20$ $\%$ ) in the presence of $\mathrm{Ca}$ and $\mathrm{K}$ (Cassie et al., 2015). Contrary to the seed, the thermochemical conversion of the pod may not produce slagging and fouling due to the absence of non-metals like $\mathrm{P}$ and $\mathrm{Cl}$. Also, the pod could be a good source of fertilizer due to the high $K$ concentration. Oasmaa and Meier (2005) showed that the presence of $\mathrm{K}$ may strongly promote the formation of water in the resulting liquid fraction, thus lowering its quality as fuel.

\begin{tabular}{|c|c|c|c|c|c|c|c|c|}
\hline \multirow[t]{2}{*}{ Sample } & \multicolumn{8}{|c|}{ Element (\% Weight) } \\
\hline & $\mathrm{O}$ & $\mathrm{F}$ & $\mathrm{Mg}$ & $\mathrm{Si}$ & $P$ & $\mathrm{Cl}$ & $K$ & $\mathrm{Ca}$ \\
\hline Seed & 39.73 & 2.82 & 13.58 & 1.25 & 1.20 & 1.69 & 22.39 & 17.35 \\
\hline Pod & 43.99 & 3.29 & 2.36 & 1.71 & None & None & 42.04 & 6.61 \\
\hline $\begin{array}{l}\text { Miscantus gigantus } \\
\text { (Vassilev et al., 2010) }\end{array}$ & & & 3.01 & 56.2 & 5.04 & & 19.75 & 10.77 \\
\hline $\begin{array}{l}\text { Switch grass } \\
\text { (Vassilev et al., 2010) }\end{array}$ & & & 4.73 & 66.25 & 39.2 & & 9.64 & 10.21 \\
\hline $\begin{array}{l}\text { Wheat Straw } \\
\text { (Vassilev et al., 2010) }\end{array}$ & & & 4.66 & 50.35 & 4.13 & & 24.81 & 8.21 \\
\hline $\begin{array}{l}\text { Rice Straw } \\
\text { (Vassilev et al., 2010) }\end{array}$ & & & 2.71 & 77.20 & 0.98 & & 12.89 & 2.96 \\
\hline
\end{tabular}

Table 4: EDX analysis of Bauhinia monandra seed and pod in comparison with Miscantus gigantus, Switch grass, Wheat Straw and Rice Straw

\section{Kinetic parameters}

The kinetic parameters for Bauhinia monandra seed and pod are presented in Table 5. The kinetic parameter of a lignocellulosic material measures the reactor performance during thermochemical conversion. Assuming that the reaction is a First Order reaction, the kinetic parameter of the seed and pod during pyrolysis was derived equation deduced from Coats and Redfern (Coats and Redfern, 1964).

\begin{tabular}{lll}
\hline Sample & $\begin{array}{l}\text { Activation energy } \\
\text { (Ea) }(\mathrm{kJ} / \mathrm{mol} .)\end{array}$ & $\begin{array}{l}\text { Frequency } \\
\text { factor(A) }\left(\mathrm{s}^{-1}\right)\end{array}$ \\
\hline Seed & 35.5 & $3.61 \times 10^{-5}$ \\
Pod & 41.56 & $1.03 \times 10^{-5}$
\end{tabular}

Table 5: Kinetics parameters of Bauhinia monandra seed and pod 
The overall kinetic reaction is given as follows:

$\frac{d b}{d t}=K f(b)$

(a)

Where $b$ is the amount of volatilized material

$b=\frac{w-w_{f}}{w_{0}-w_{f}}$

(b)

During decomposition, ' $W_{f}$ ' is the final weight of the biomass; ' $w_{0}$ ' is the initial weight of the biomass that decomposes to mass ' $w$ ' at a time (t). $K$ is the rate constant and $f(b)=(1-b)^{m}$ and $m$ is the order of the reaction.

Following the Arrhenius equation, the rate constant $\mathrm{K}$ is temperature dependent and it is given as:

$$
K=A \exp \left(-\frac{E a}{R T}\right)
$$

(c)

In equation (3) $A$ is the frequency factor in $\left(\mathrm{s}^{-1}\right)$, Ea is the activation energy in $(\mathrm{kJ} / \mathrm{mol}), T$ is the temperature in $(\mathrm{K})$ and $\mathrm{R}$ is the gas constant in $(\mathrm{J} / \mathrm{K} / \mathrm{mol})$.

Integrating equation (1) with the consideration of equation (2) and (3) for a first-order reaction gives:

$\ln \left[-\frac{1}{w_{0}-w_{f}} \frac{d w}{d t}\right]=\ln (A)-\left(\frac{E a}{R T}\right)+\operatorname{mln}[(w-$

$\left.\left.w_{f}\right) /\left(w_{0}-w_{f}\right)\right]$

The linear form of this equation is:

$\mathrm{y}=L+N \mathrm{x}+K \mathrm{z}$

$\mathrm{y}=\ln \left[-\frac{1}{w_{0}-w_{f}} \frac{d w}{d t}\right]$

$x=1 / T$

$\mathrm{L}=\ln (A)$ which is the intercept

$\mathrm{N}=-\mathrm{Ea} / \mathrm{T}$ which is the slope

$\mathrm{K}=\mathrm{m}$ which is the order of the reaction

$\mathrm{z}=\ln \left[\left(w-w_{f}\right) /\left(w_{0}-w_{f}\right)\right]$

Thus, a plot of $\ln \left[-\frac{1}{w_{0}-w_{f}} \frac{d w}{d t}\right]$ against $\frac{1}{T}$ gives a straight line, the slope will give the activation energy after being multiplied by $R$ and the intercept equals to $\ln \mathrm{A}$.
The Activation Energy of the pod $(41.56 \mathrm{~kJ} / \mathrm{mol})$ is higher compared to that of seed $(35.5 \mathrm{~kJ} / \mathrm{mol})$. These values are higher compared to that reported for Cotton stalk $(25.7 \mathrm{~kJ} / \mathrm{mol})$, Corn Stalk $(26.2 \mathrm{~kJ} / \mathrm{mol})$ and Rice Straw $(26.1 \mathrm{~kJ} / \mathrm{mol})$ respectively (Abhishek and Jillian, 2016). The non-agreement may be attributed to the difference in particle size, heating rate, morphology as well as the chemical structure of the biomass (Ledakowicz and Stolarek, 2002). The frequency factor of the pod $\left(1.03 \times 10^{-5} \mathrm{~s}^{-1}\right)$ is comparable to that of seed $\left(3.61 \times 10^{-5} \mathrm{~s}^{-1}\right)$. These values are lower compared to that reported for Cotton stalk $\left(5.86 \times 10^{-3} \mathrm{~s}^{-1}\right)$, Corn Stalk (6.95 x 10$\left.{ }^{3} \mathrm{~s}^{-1}\right)$ and Rice Straw $\left(6.95 \times 10^{-3} \mathrm{~s}^{-1}\right)$ respectively (Abhishek and Jillian, 2016). The lower the activation energy, the higher the rate of reaction. Hence, the rate of decomposition of the components in the seed will be faster than that of the pod because of the low Ea value compared to the pod.

\section{Thermogravimetric analysis}

The TGA and DTG curves of $B$. monandra pod and seed are presented in Figs. 1 and 2. The thermogravimetric analysis of both seed and pod reveals four distinct stages of mass loss. The first stage of the pyrolysis indicates the evaporation of intrinsic water at about $100{ }^{\circ} \mathrm{C}$. The percentage (weight loss) due to drying of the water molecule in a pod $(2.35 \%)$ was high compared to that of seed (1.33\%).

The second stage pyrolysis occurred at a temperature of $261.46^{\circ} \mathrm{C}$ for seed and $302.37^{\circ} \mathrm{C}$ for pod may be attributed to the decomposition of hemicellulose. According to Yang et al., 2007, hemicellulose decomposes at a temperature range of $220-315{ }^{\circ} \mathrm{C}$. The percentage (weight loss) during pyrolysis for hemicellulose is lower in the seed (17.99\%) compared to the pod $(20.83 \%)$. The value obtained during proximate analysis for hemicellulose in the seed $(20 \%)$ is close to the weight loss (17.99\%) obtained during pyrolysis but the observed value for the pod $(33.5 \%)$ is significantly different from the weight loss (20.83\%) during pyrolysis 


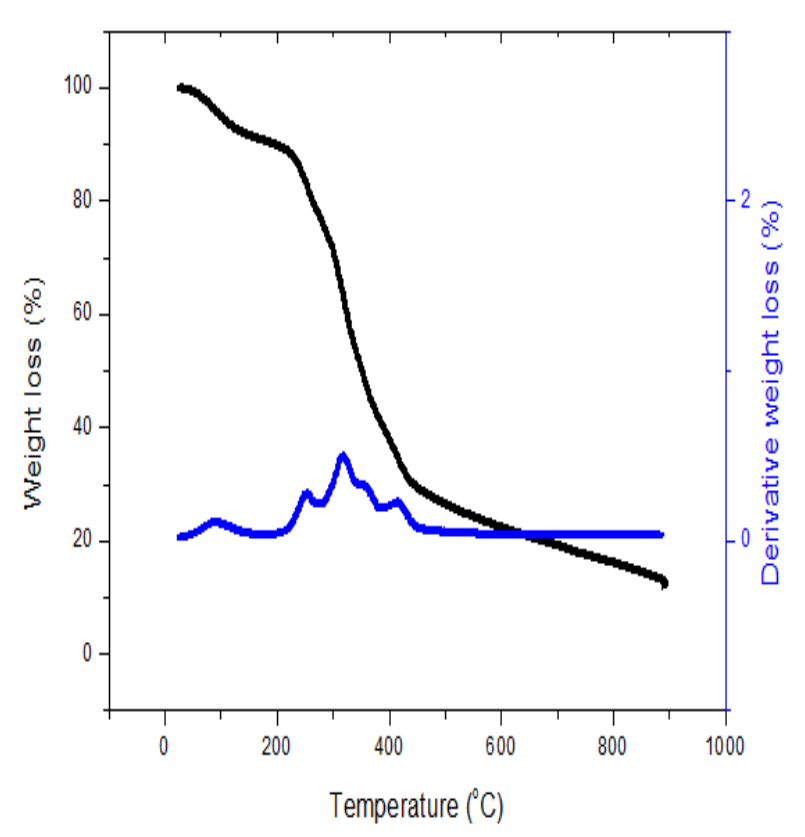

Fig. 1: Thermogravimetric analysis (TGA and DTG) of Bauhinia monandra seed

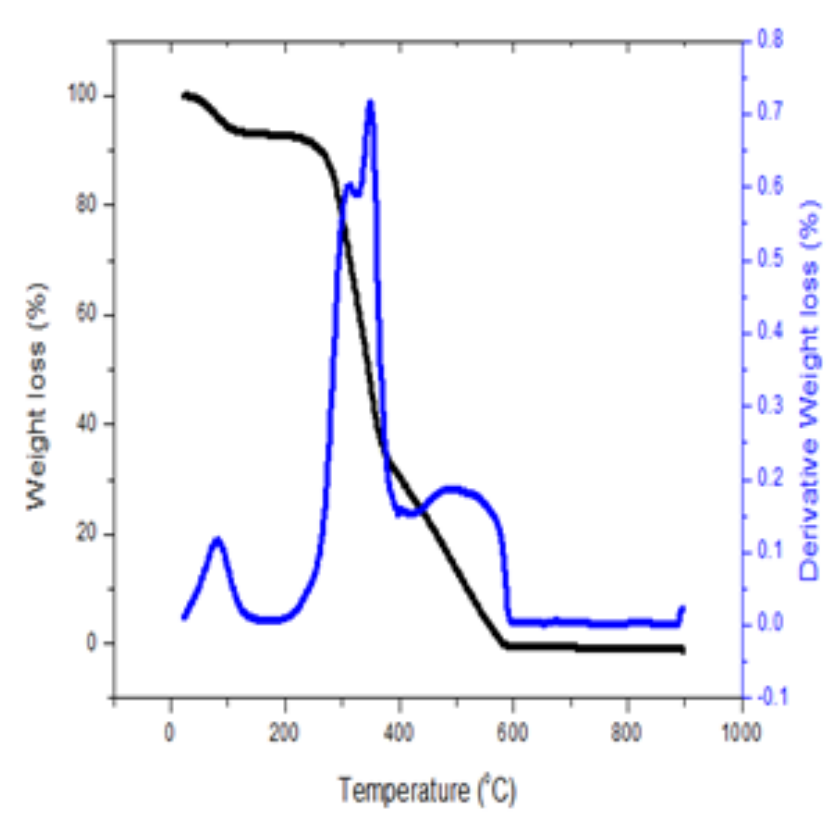

Fig. 2: Thermogravimetric analysis (TGA and DTG) of Bauhinia monandra pod

The third stage pyrolysis occurring at a temperature of $309.37^{\circ} \mathrm{C}$ for seed and $345.88^{\circ} \mathrm{C}$ for pod which could be attributed to the decomposition of cellulose. The cellulose content of a biomass sample decomposes at a temperature range of $315-400{ }^{\circ} \mathrm{C}$ (Yang et al., 2007). The percentage (weight loss) of decomposed cellulose for the seed $(23.65 \%)$ and pod (26.52\%) are similar. The observed value for cellulose in the seed (43.5\%) and pod (37.5\%) during proximate analysis are higher compared to the $\%$ weight loss of the cellulose in both seed and pod.

Finally, the fourth stage pyrolysis occurring at a temperature of $385.49^{\circ} \mathrm{C}$ for seed and $517^{\circ} \mathrm{C}$ for pod may be due to the decomposition of lignin. Yang et al., 2007 recorded a temperature range of $100-900{ }^{\circ} \mathrm{C}$ for the decomposition of lignin. The percentage (weight loss) of decomposed lignin in a pod (39.88) is higher compared to that of seed (15.79). The recorded value for lignin in the seed $(19.5 \%)$ during proximate analysis is comparable with the value of decomposed lignin during pyrolysis while that of the pod $(39.88 \%)$ is significantly different from the $\%$ weight loss.

The differences obtained in the proximate analysis result and pyrolysis values using thermogravimetric method could be due to their different reaction environment; while the thermogravimetric analysis was due in nitrogen environment the, the proximate was under room condition and oxygen environment.

\subsection{Scanning Electron Microscopy}

The SEM photograph of the two samples as presented in Figs. 3a and $3 b$ showed a marked difference in their morphology. While the seed morphology presents the material as a round ball like and an aggregated clumps of solid, the morphology of the pod revealed it to be in a form of tread like straight fiber materials. The morphology suggests that the pod could contain more of cellulose fiber material than that of the seed, but that was not the case from the proximate analysis in which the seed has higher cellulose content than the pod. 

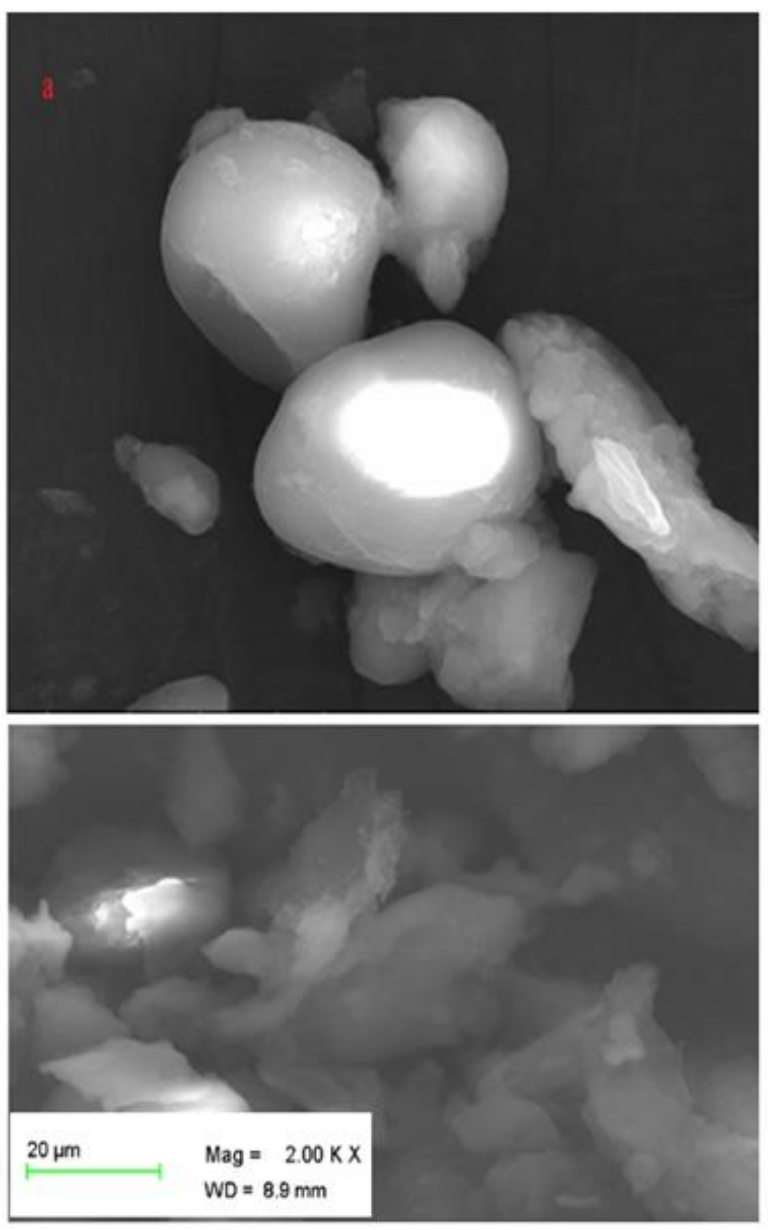

Fig. 3 a, b: SEM of Bauhinia monandra seed

\section{MATERIALS AND METHOD}

\section{Sample Collection and Preparation}

For this experiment, pods of Bauhinia monandra containing seeds were harvested from the mother plant within the campus of Federal University of Technology, Akure, Ondo State, Nigeria. The seeds and the pods were separated by breaking the harvested pods of Bauhinia monandra to obtain the seed. The pods were then air dried in the laboratory environment to a constant moisture content of $10 \%$, after which the pods were ground to powder form and sieved to obtain a material with a particle size of $425 \mu \mathrm{m}$. This was stored in an airtight container for the subsequent experiment.
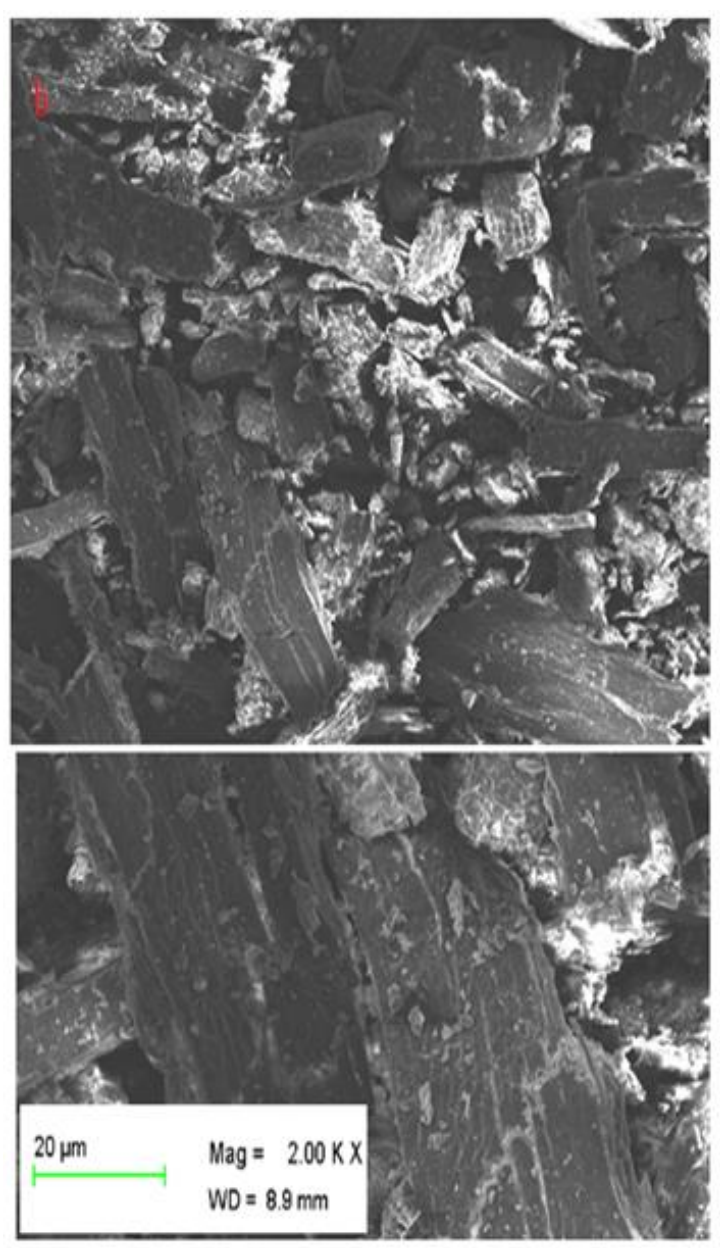

The Bauhinia monandra seed and pod were authenticated at the Department of Crop, Soil and Pest Management of the Federal University of Technology, Akure, Ondo State, Nigeria. $\mathrm{NaOH}$, benzene, ethanol, and $\mathrm{H} 2 \mathrm{SO} 4(98 \%)$ were obtained from Sigma-Aldrich. All the chemicals were analytical grade used as received.

\section{Experimental}

\section{Chemical Composition of Sample}

In the determination of chemical composition done by (Moubasher et al., 1982), the dissolved lignin after fiber treatment with $24 \% \mathrm{KOH}$ was not taken into consideration, in our past study (Oluwasina et al., 2014) we were able to isolate alkaline dissolved lignin, which most of the time is poured away with the solution after the 
alkaline treatment. Thus, in this modification, the dissolved lignin was isolated and added to the residue (the lignin) obtained after $72 \% \mathrm{H}_{2} \mathrm{SO}_{4}$ treatment of the fraction C. Exactly $2 \mathrm{~g}$ of sample was refluxed in with 2:1 benzene-ethanol for $8 \mathrm{~h}$, washed thoroughly with distilled water and kept in an oven at $40{ }^{\circ} \mathrm{C}$ overnight to obtained constant weight sample. The after the refluxed material was given various chemical treatments and different fractions were obtained as follows; the refluxed sample (Fraction A) was treated with $20 \% \mathrm{NaOH}(\mathrm{w} / \mathrm{v})$ at solid to liquor ratio of 1:30 in a covered container for $4 \mathrm{~h}$ at room temperature. After the reaction time, the solution was filtered to obtain the fiber sample and the filtrate. The $\mathrm{pH}$ of the filtrate was adjusted to 2 and heated at $80{ }^{\circ} \mathrm{C}$ for $2 \mathrm{~h}$ to obtain its contained dissolved lignin in solid form (obtained lignin is denoted as Fraction $\mathrm{B}$ ), this was washed to neutral and dried at $80{ }^{\circ} \mathrm{C}$ to constant weight. The obtained fiber sample was denoted as Fraction $\mathrm{C}$. This fraction $\mathrm{C}$ was treated with $72 \% \mathrm{H}_{2} \mathrm{SO}_{4}(\mathrm{v} / \mathrm{v})$ for $3 \mathrm{~h}$ to hydrolyze the cellulose, the obtained fiber was then refluxed with $5 \% \mathrm{H}_{2} \mathrm{SO}_{4}$ for $2 \mathrm{~h}$, after which the sample was washed to neutral using distilled water and dried to constant weight in an oven at $80^{\circ} \mathrm{C}$. This final residue was denoted fraction $\mathrm{D}$. Chemical composition of the sample was calculated using the following equations;

Cellulose $=C-D$

Hemicellulose $=\mathrm{A}-\mathrm{C}$

Lignin $=B+D$

\section{Proximate Composition of Sample}

The proximate analysis for the determination of moisture content, volatile matter, ash content, and fixed carbon was done using Perkin Elmer STA 6000.

\section{Ultimate Analysis of Sample}

Ultimate analysis for the determination of carbon, hydrogen and sulfur content was determined using Perkin Elmer CHNS/O.

\section{Instrumental Analysis of Sample}

Scanning Electron Microscope (SEM) coupled with-Energy Dispersed X-ray (EDX) (FEI FIB/SEM Nova 600 Nanolab) was used for the morphological characteristic and elemental composition of the samples. The samples were prepared for SEM by double-coating with a palladium and gold alloy. Thermogravimetric Analysis (TGA) (Perkin Elmer STA 6000) in a nitrogen atmosphere, flow rate $20 \mathrm{~mL} \mathrm{~min}^{-1}$ at a temperature $\left(30\right.$ and $\left.900^{\circ} \mathrm{C}\right)$ and heating rate 10 ${ }^{\circ} \mathrm{C} \mathrm{min}^{-1}$, about $10.0 \mathrm{mg}$ sample was used for the thermal stability determination.

\section{CONCLUSION}

In this research, the thermochemical characterization of Bauhinia monandra seed and pod were performed. The proximate and ultimate analyses showed that the biomass contains high volatile matter, low ash content, high carbon content, low sulfur content, and relatively high HHV compared to fast-growing biomass. Also, the biochemical composition of the seed and pod revealed a considerable amount of cellulose and lignin which makes them potentially useful for bio-oil production. The biomass ash composition of the seed reported a reasonably high amount of alkali metals ( $\mathrm{K}, \mathrm{Ca}$ and $\mathrm{Mg}$ ) in the presence of some non-metals ( $\mathrm{P}$ and $\mathrm{Cl})$. Hence, there is a possibility of the occurrence of slagging and fouling of the furnace during thermochemical conversion. However, this tendency can minimize by the application of the pre-treatment process. The kinetics parameter (Ea and $\mathrm{A}$ ) derived from the correlation of TGA/DTG data with Arrhenius equation reveals relatively high activation energy (Ea) compared to much fastgrowing herbaceous biomass due to the high level of crystallinity attributed to high cellulose content. Finally, the thermogravimetric analysis of seed and pod showed four (4) degradation peaks which are attributed to the evaporation of intrinsic water around $100{ }^{\circ} \mathrm{C}$ and the decomposition of hemicellulose, cellulose and lignin in the range of $262-302{ }^{\circ} \mathrm{C}, 309-346{ }^{\circ} \mathrm{C}$ and $386-517{ }^{\circ} \mathrm{C}$ respectively. These characteristics deemed the biomass (Bauhininia 
monandra seed and pod) beneficial as a good source of bioenergy from an economical and environmental point of view.

\section{CONFLICT OF INTEREST}

All the authors in this research unanimously agree to submit our manuscript to this reputable journal and declare that there are no conflicts of interest in the publication

\section{REFERENCES}

Abhishek, S. P. and Jillian, I. G. 2016, 'Continuous activation energy representation of the Arrhenius equation for the pyrolysis of cellulosic materials: feed corn stover and cocoa shell biomass', Cellulose Chemistry and Technology, vol. 50, no.2, pp. 311-320. Adeyinka, A. 2012, 'Determination of Heating Value of Five Economic Trees Residue as a Fuel for Biomass Heating System,' Nature and Science 2012, vol.10, pp. 26-29.

Agbede, J.O. 2006, 'Characterization of the leaf meals protein concentrates, and residues from some tropical leguminous plants', J. Sci. Food. Agric, vol. 86, pp. 1292-1297.

Agbugui, M., Oniye, S.J., and Auta, J. 2010, 'Effects of processing on the mineral content proximate composition and phytochemical factors of the seeds of Bauhinia monandra (Kurz)', Bayero Journal of Pure and Applied Sciences, vol. 3, pp. $23-25$.

Argolo, A.C.C., Sant'Ana, A.E.G., Pletsch, M., and Coelho, L.C.B.B. 2004, 'Antioxidant activity of leaf extracts from Bauhinia monandra, Bioresources Technology, vol.95, pp. 229-233.

Baskar, C., Baskar S., Dhilon, R.S. 2012, 'Biomass Conversion The interface of Biotechnology', Chemistry and Materials science, vol. 46, pp. 435-457. Bizzo, A.W., Lenc, P.C., Carvalho, D.J., Veiga, J.P.S. 2014, 'The generation of residual biomass during the production of bio-ethanol from sugarcane its characterization and its use in energy production', Renew. Sustain. Energy Rev, vol.29, pp.589-603.

Carrier, M., Loppinet-Serani, A., Denux, D., Michel, L. J., Ham-Pichavant, F., Cansell, F., Aymonier, C. 2011, 'Analysis as a new method to determine the lignocellulosic composition of biomass', Biomass Bioenergy, vol.35, pp.298-307.

Cassie, M. W., Vimal, K. B., Carloalberto, P., Krishan, M. R., Seth, D., and Venugopal, M. 2015, 'Engineering Plant Biomass Lignin Content and Composition for Biofuels and Bioproducts. A review', Energies vol. 8, pp.7654-7676.
Coats, A. W., and Redfern, J.P. 1964, 'Kinetic parameters from thermogravimetric data', Nature Science, vol. 201, pp. 68-69

Dermibas, A. 1996, 'Calculation of higher heating values of biomass fuels', Fuel, vol. 76, pp. 431-434.

Diaz-Ramirez, M., Boman, C., Sebastian, F., Royo, J., Xiong, S.J., Boström, D. 2012, 'Ash characterization and transformation behavior of the fixed-bed combustion of novel crops: poplar, brassica, and cassava fuels', Energy Fuel, vol. 26, pp. 3218-3229 Eduardo, C., Braza, M., Paula M. C. 2014, 'Physical Chemical Characterization of Biomass Samples for Application in Pyrolysis Process, Chemical Engineering Transactions, vol.37, pp. 523-528.

García, R., Pizarro, C., Lavín, A.G., Bueno, J.L. 2012, 'Characterization of Spanish biomass waste for energy use', Bioresour. Technol, vol. 103, pp. 249258.

lyer, P.V.R., Rao T.R., Grover P.D. 2002, 'BiomassThermo-chemical characterization', 3rd edn, MNES, New Delhi, pp. 195-200.

Kurchania, A.K., Panwar, N.L., Pagar, S.D. 2010, 'Design and performance evaluation of biogas stove for community cooking application', Int I Sustain Energy vol.29, pp. 116-123

Ledakowicz, S., and Stolarek, P. 2002, 'Kinetics of Biomass Thermal Decomposition', Chem. Process Eng, vol. 27, pp. 1309-1323.

Martinez-Angel, D., Villamizar-Gallardo, R. A., OrtízRodríguez, O. O. 2015, 'Characterization and evaluation of cocoa (theobroma cacao l.) pod husk as a renewable energy source', Agrociencia, vol.49 pp. 329-345.

Mendu, V., Harman-Ware, A.E., Crocker, M., Jae, J., Stork, J., Morton, S., 3rd; Placido, A., Huber, G., Debolt, S. 2011, 'Identification and thermochemical analysis of high-lignin feedstocks for biofuel and biochemical production', Biotechnol. Biofuels, vol. 4. Mohammed, Y. I., Yousif, A. A., Feroz, K. K., Suzana, Y., Ibraheem, A., and Soh, A. C. 2015, 'Comprehensive Characterization of Napier Grass as a Feedstock for Thermochemical Conversion', Energies, vol. 8, pp. 3403-3417.

Moubasher, M.H., Abdel-Hafez, S.I., Abdel-Fattah, H.M., and Mohanram, A.M. 1982, 'Direct estimation of Cellulose, Hemicellulose and Lignin', J Agricu Res, vol. 46. pp. 1467-1476.

Mukome, F. N. D., Zhang, X., Silva, L. C. R., Six, J., \& Parikh, S. J. 2013, 'Use of chemical and physical characteristics to investigate trends in biochar feedstocks', Journal of Agricultural and Food Chemistry, vol. 61, no.9, pp. 2196-2204. 
Oasmaa, A., and D, Meier. 2005, 'Norms and standards for fast pyrolysis liquids: 1 . Round robin test', J. Analyt. Appl. Pyrolysis, vol. 73, pp. 323-334. Oluwasina, O. O., Lajide, L., and Owolabi, B. J., 2014, 'Performance of bonded boards using lignin-based resin', Wood Material Science \& Engineering, vol.10, pp.168-177.

Parikh, J., Channiwala, SA., Ghosal, GK. 2005, 'A Correlation for calculating HHV from proximate analysis of solid fuels. Fuel, vol. 84, pp. 487-94.

Peter, McKendry 2002, 'Energy production from biomass (part 1): overview of biomass A Review. Bioresource Technology, vol. 83, pp. 37-46.

Raclavska, H., Juchelkova, D., Roubicek, V., Matysek, D. 2011, 'Energy utilization of biowaste-sunflowerseed hulls for co-firing with coal', Fuel Process. Technol, vol.20, pp. 1036-1042.

Risser, P. G. 1981, 'Agricultural and forestry residues', Biomass Conversion Processes for Energy and Fuels, vol. 1, pp. 213-215

Salaheldeen, M., Aroua, M.K., Mariod, A.A., Sit, F.C., Malik, A. A. 2014, 'An evaluation of Moringa peregrina seeds as a source for bio-fuel', Industrial Crops and Products, vol. 61, pp. 49-61

Sarfraz, A., Sherazi, S.T.H., Bhanger, M.I., Farah, N.T., Mahesar, S.A., 2009, 'Oxidative stability assessment of Bauhinia purpurea seed oil with a comparison to two conventional vegetable oils by Differential Scanning Calorimetry and Rancimat methods', Themochemica Acta, vol.484, pp. 1-3.

Schmidt, M.W., Noack, A.G. 2000, 'Black carbon in soils and sediments: analysis, distribution, implications, and current challenges', Glob Biogeochem Cycles, vol.14, no.3, pp. 777-793.

Stella-Mary, G., Sugumaran, P., Niveditha, S., Ramalakshmi, B., Ravichandran, P. and Seshadri, S. 2016, 'Production, characterization and evaluation of biochar from pod (Pisum sativum), leaf (Brassica oleracea) and peel (Citrus sinensis) Wastes', International Journal of Recycling of Organic Waste in Agriculture, vol. 5, pp. 2016, 43 -. 53

Suarez, J. A., Carlos, A. L., Felix, F. F., Guilherme, B. 2000, 'Thermochemical properties of cuban biomass,' Energy sources, vol.22, pp. 851-857.

US Department of Energy. 2011. U.S. 'Billion-Ton Update: Biomass Supply for a Bioenergy and bioproducts Industry', R.D. Perlack and B.J. Stokes (Leads), ORNL/TM-2011/224. Oak Ridge National Laboratory, Oak Ridge, TN. Retrieved from: http://energy.gov/sites/prod/files/2015/01/f19/billi on ton update 0.pdf

Valantinavičius, M., Vonžodas, T. 2012, 'Proximate and elemental analysis of solid biofuel and influence to combustion process' presented at 9th International conference on energy issues, 2012 Lithuania, Lithuanian energy institute, EasyBib Publishing.

Vassilev, S. V., David, B., Lars, K. A., Christina, G. V. 2010, 'An overview of the chemical composition of biomass. A Review article', Fuel, vol. 89, pp. 913-933 Yang, H., Yan, R., Chen, H., Lee, D.F., Zheng, C. 2007, 'Characteristics of hemicellulose, cellulose and lignin pyrolysis', Fuel, vol.86, pp.1781-1788.

Yang, Q., and Wu, S. 2009, 'Thermogravimetric characteristics of wheat straw lignin', Journal of Cellulose Chem. Technol, vol. 43, pp. 133-139 